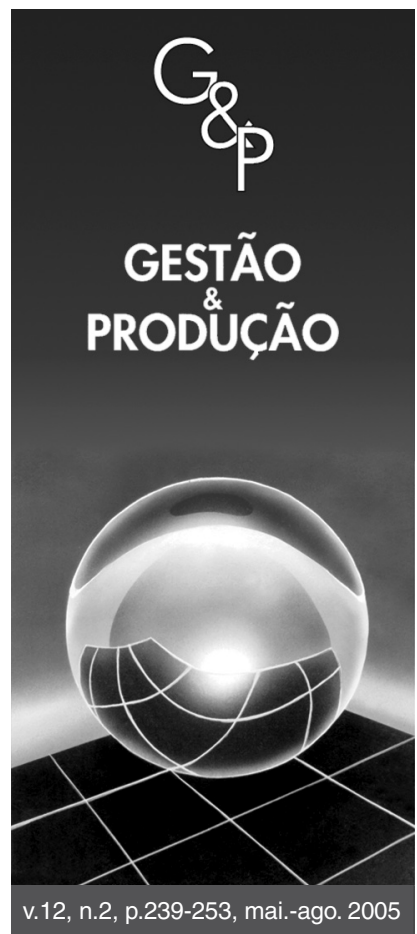

\title{
DEFINIÇÃO DO PRAZO DE GARANTIA DE UM PRODUTO OTIMIZADO EXPERIMENTALMENTE
}

\author{
Morgana Pizzolato \\ Carla Schwengber ten Caten \\ Flávio Sanson Fogliatto \\ Departamento de Engenharia de Produção e Transportes, \\ Universidade Federal do Rio Grande do Sul, \\ $2^{\circ}$ andar, sala LOPP, Praça Argentina, 9, CEP 90040-020, Porto Alegre, RS, \\ e-mail: morgana@producao.ufrgs.br, tencaten@producao.ufrgs.br, \\ ffogliatto@producao.ufrgs.br
}

\section{Resumo}

Recebido em 28/1/2004 Aceito em 07/6/2005

Este artigo documenta os resultados da aplicação de um método para otimização de aspectos da qualidade e vida útil para posterior definição do prazo de garantia de produtos que não falham, mas degradam até uma condição considerada aceitável. O método de otimização é composto pelas seguintes etapas: i) caracterização do problema; ii) planejamento e execução dos experimentos; iii) modelagem das variáveis de resposta; iv) otimização; e v) modelagem da vida útil e definição do prazo de garantia. As etapas metodológicas contemplam o uso de QFD (Desdobramento da Função Qualidade), de Projeto de Experimentos, modelos de regressão de ensaios acelerados e modelos de degradação. Para a otimização e determinação do prazo de garantia, é apresentado um procedimento que utiliza uma sequiência de passos em que ferramentas estatísticas, como análise de regressão e modelagem de dados de degradação, são empregadas. Somado a isso, são utilizados procedimentos de avaliação sensorial para avaliar os níveis de degradação das amostras do produto. O método é aplicado em um produto utilizado na criação de animais.

Palavras-chave: otimização, testes de degradação acelerados, modelagem do tempo de vida de produtos.

\section{Introdução}

Para manter seus produtos no mercado com os níveis demandados de qualidade, empresas industriais necessitam de ferramentas eficazes para o desenvolvimento e otimização de produtos. A maioria das empresas de manufatura, em particular aquelas que competem em mercados internacionais, alocam uma grande quantidade de recursos no projeto de produtos confiáveis (Nelson, 1988; Wasserman e Sudjiato, 1996). A qualidade do produto, conforme percebida pelo consumidor, e seu prazo de garantia são fatores determinantes no momento da compra.

Garantia pode ser definida como um contrato ou acordo que estabelece que o produtor de um produto ou serviço deve concordar em reparar, repor ou oferecer a assistência necessária quando o produto falha ou o serviço não atende às demandas do usuário, antes de um momento pré-especificado no tempo, correspondente à duração da garantia (Elsayed, 1996). Tempo, no contexto da definição, pode ser medido em unidades de tempo de calendário, tais como horas, meses ou anos, ou em unidades de uso, como milhas, horas de operação ou o número de utilizações do produto (por exemplo, o número de cópias feitas por uma máquina copiadora).

Estudos para definição de políticas ótimas de garantia em produtos vêm crescendo em importância nos últimos anos, com o aumento da concorrência entre empresas em diferentes mercados. Produtos similares quanto à função, preço e qualidade são selecionados pelo consumidor, na hora da compra, com base na garantia que oferecem. Assim, muitos produtores estão sendo forçados a oferecer garantias antes inexistentes ou a estender prazos de garantia como forma de assegurar a venda futura de seus produtos. 
Alguns produtos apresentam problemas de desempenho durante o prazo de garantia. Quando isso acontece, se faz necessária uma avaliação da vida útil do produto, considerando aspectos relacionados ao processo produtivo, tais como parâmetros de processo, e aspectos de projeto, tais como a composição do produto. O prazo de garantia de um produto pode ser definido em estudos de confiabilidade, por meio da estimação de sua taxa de falha e vida útil esperada. Estudos de confiabilidade, todavia, podem demandar tempo e recursos financeiros excessivos.

Para avaliar a vida útil do produto, podem-se utilizar variáveis de resposta que meçam o seu grau de degradação (Nelson, 1990). Avalia-se, assim, a redução no desempenho do produto antes da sua falha. Variáveis de resposta de degradação podem ser avaliadas sob condições extremas de uso do produto, por meio da utilização de fatores de aceleração que permite reduzir o tempo total de experimentação.

Neste artigo, propõe-se um método de otimização experimental capaz de lidar com variáveis de resposta de degradação, além das variáveis de resposta usuais de qualidade. O método inova ao possibilitar o uso de variáveis de resposta sensoriais de degradação no processo de otimização. Por exemplo, a degradação apresentada pelo produto exposto a mecanismos de degradação é avaliada visualmente, em um painel de especialistas, como no estudo de caso que ilustra a aplicação do método neste artigo. Tal cenário pode constituir, em diversas aplicações industriais, a única alternativa economicamente viável para avaliar as variáveis de resposta de degradação, o que justifica a proposição do método aqui apresentado.

O método proposto pode ser resumido nas seguintes etapas (Pizzolato, 2002):

i) Caracterização do problema: consiste em organizar e documentar as informações existentes sobre o caso em estudo. Nesta etapa, estabelecem-se os objetivos do estudo, identificam-se as características de qualidade (CQs) de interesse e variáveis de resposta que as representam, define-se o sistema de medição das variáveis de resposta, inclusive o da variável de resposta de degradação, que pode ser realizada por avaliação sensorial e listam-se os parâmetros do processo que influenciam as variáveis de resposta, bem como seus intervalos de investigação;

ii) Planejamento e execução dos experimentos: consiste na elaboração de uma matriz de causa e efeito, segundo a estrutura das matrizes do QFD - Quality Function Deployment (Akao, 1990), para priorizar os fatores controláveis, baseados na intensidade de relacionamento com as variáveis de resposta e na sua facilidade de ajuste. Também são definidos o número de níveis e possíveis interações entre os fatores controláveis, fatores a serem mantidos constantes e fatores de ruído. Por fim, planejam-se, executam-se e analisam-se os experimentos segundo os princípios do Projeto de Experimentos (Montgomery, 1997), considerando a execução de testes acelerados para reduzir o tempo de execução dos experimentos (Nelson, 1990; Meeker e Hahn, 1985);

iii) Modelagem das variáveis de resposta: nesta etapa, modelam-se a média e variância das múltiplas variáveis de resposta do produto associadas à qualidade e à degradação como função dos fatores controláveis manipulados experimentalmente. Para tanto, utilizam-se modelos de regressão múltipla (Seber, 1984);

iv) Otimização: propõe-se a utilização da Função Perda Quadrática Multivariada apresentada em Ribeiro e Elsayed (1995) para definir os níveis ótimos dos fatores controláveis; e

v) Modelagem da vida útil e definição do prazo de garantia: trata-se da última etapa do método, na qual se define, para a variável de resposta de degradação, o fator de estresse e a matriz experimental a ser usada nos testes de degradação. Realizam-se os testes de degradação acelerada com o produto otimizado para se obterem dados que serão utilizados na modelagem da vida útil do produto (Nelson, 1990; Elsayed, 1996) e procede-se à definição de seu prazo de garantia.

O método aqui utilizado teve como ponto de partida as proposições de Ribeiro et al. (2000) e Caten (1995). Tais autores, todavia, não contemplavam variáveis de degradação em seus métodos, conforme proposto neste artigo. Para ilustrar o método de otimização aqui proposto, apresenta-se um estudo de caso, no qual se deseja otimizar a formulação de pisos plásticos, fabricados em um processo de injeção e utilizados na criação de animais, com relação a aspectos de qualidade e confiabilidade.

As sessões, que se seguem, detalham e exemplificam as etapas para a otimização experimental do produto e definição do prazo de garantia. Também são apresentadas conclusões a respeito do método e dos resultados obtidos.

\section{Método de otimização experimental e estudo de caso}

Nesta seção, são apresentadas as etapas propostas do método de otimização de produtos e processos, bem como os resultados da sua aplicação no estudo de caso.

\subsection{Caracterização do problema}

Nesta etapa, a equipe de trabalho estabelece os objetivos do estudo, definindo metas e sistemáticas para sua verificação. Na maioria dos produtos, as principais características de qualidade requeridas pelo cliente correspondem àquelas essenciais para o sucesso e operação segura 
do produto (Goel e Singh, 1998). Um segundo grupo de características de qualidade é definido por tendências do mercado para a classe de produtos em estudo; clientes comparam produtos concorrentes baseados nestas características. Tais características de qualidade podem estar baseadas em descobertas tecnológicas ou idéias inovadoras. Um produto de boa qualidade deve atender a todas essas características de qualidade, além de apresentar-se duradouro. Falhas no produto como um todo ou em algumas de suas características de qualidade essenciais dentro de seu período de vida planejado geram insatisfação no cliente. Tal período é definido em estudos de Confiabilidade. Se, por outro lado, o desempenho das características de qualidade do produto degrada conforme esperado, o produto é identificado como de boa durabilidade, o que aumenta sua aceitação junto aos consumidores.

A equipe de trabalho deve dirigir seus esforços na identificação das demandas de qualidade de interesse do mercado e na definição de características de qualidade diretamente relacionadas a essas demandas. As características de qualidade selecionadas devem traduzir as demandas de qualidade em termos de requisitos técnicos, mensuráveis e objetivos (Montgomery, 1997). Para tanto, recomendam-se equipes de trabalho cujos integrantes possuam familiaridade com o produto e seu processo de fabricação (Ribeiro et al., 1999).
$\mathrm{Na}$ otimização dos pisos plásticos, as características de qualidade de interesse para o cliente foram identificadas por um grupo de trabalho multifuncional, formado por funcionários dos setores de projeto, de processo e de atendimento ao cliente. Identificadas as demandas, elegeram-se características de qualidade a elas relacionadas e candidatas à experimentação. As características de qualidade foram avaliadas quanto à sua importância, tendo como base o conhecimento do grupo multifuncional, além de demandas definidas pelos clientes. O conjunto de características de qualidade resultantes, seus valoresalvo e especificações, bem como sua importância relativa percentual, vêm apresentados na Tabela 1 .

No estudo de caso, uma das características de qualidade selecionadas para estudo diz respeito à queda de desempenho ou degradação do produto. Tal característica de qualidade está diretamente relacionada à robustez e estabilidade do produto ao longo do tempo, ou seja, à sua confiabilidade. Características de qualidade de degradação podem ser variáveis objetivamente mensuráveis ou variáveis sensoriais, avaliadas somente por meio de mensuração subjetiva (Faccioni, 2000). A característica de qualidade degradação na Tabela 1 pertence à segunda categoria. A avaliação dos pisos plásticos quanto à degradação provocada pelo seu uso intensificado (isto é, em condições aceleradas) é feita por meio de inspeção visual.

Tabela 1. Matriz de relacionamento entre características de qualidade e parâmetros de processo.

\begin{tabular}{|c|c|c|c|c|c|c|c|c|c|c|c|c|c|}
\hline \multirow[b]{2}{*}{$\begin{array}{c}\text { Características de } \\
\text { Qualidade }\end{array}$} & \multirow[b]{2}{*}{ 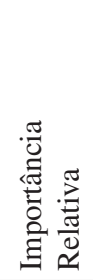 } & \multirow[b]{2}{*}{ 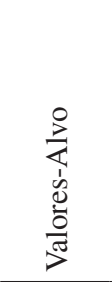 } & \multirow[b]{2}{*}{ 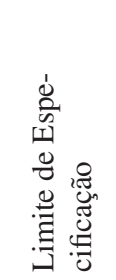 } & \multirow[b]{2}{*}{$\stackrel{̊}{\cong}$} & \multicolumn{9}{|c|}{ Parâmetros do Processo } \\
\hline & & & & & 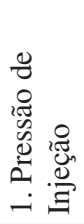 & 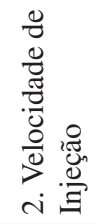 & 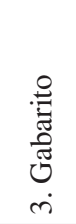 & 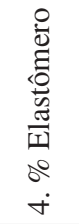 & \begin{tabular}{l}
$\frac{8}{\frac{U}{\pi}}$ \\
\multirow{\pi}{*}{} \\
$\dot{0}$ \\
$\dot{n}$
\end{tabular} & 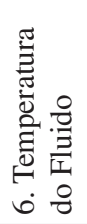 & 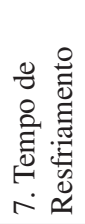 & 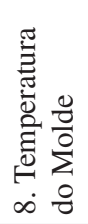 & 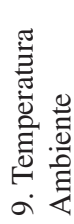 \\
\hline 1. Degradação & 26,14 & 0,106 & 0,026 & $\mathrm{Mm}$ & 1 & 1 & 0 & 2 & 2 & 3 & 0 & 9 & 0 \\
\hline 2. Custo & 21,70 & 28,24 & 29,14 & $\mathrm{~mm}$ & 0 & 3 & 0 & 9 & 9 & 2 & 9 & 1 & 0 \\
\hline 3. Dureza Rockwell & 19,52 & 94 & 50,86 & $\mathrm{Mm}$ & 0 & 0 & 0 & 3 & 9 & 0 & 0 & 0 & 0 \\
\hline 4. Impacto $\mathrm{p} /$ carga máxima & 16,98 & 1,887 & 0,724 & $\mathrm{Mm}$ & 1 & 0 & 0 & 9 & 3 & 0 & 1 & 0 & 0 \\
\hline 5. Impacto $\mathrm{p} /$ deflexão & 7,82 & 1,498 & 4,278 & $\mathrm{~mm}$ & 1 & 0 & 0 & 9 & 3 & 0 & 1 & 0 & 0 \\
\hline 6. Impacto $\mathrm{p}$ / energia & 7,82 & 3,083 & 0,495 & $\mathrm{Mm}$ & 1 & 0 & 0 & 9 & 3 & 0 & 1 & 0 & 0 \\
\hline \multicolumn{5}{|c|}{ Valor máximo } & 170 & 1200 & sem & 5 & 3 & 250 & 90 & 50 & - \\
\hline \multicolumn{5}{|c|}{ Valor mínimo } & 0 & 300 & com & 0 & 0 & 210 & 70 & 20 & - \\
\hline \multicolumn{5}{|c|}{ Unidade Medida } & Bar & $\mathrm{mm} / \mathrm{s}$ & - & $\%$ & $\%$ & ${ }^{\circ} \mathrm{C}$ & $\mathrm{s}$ & ${ }^{\circ} \mathrm{C}$ & ${ }^{\circ} \mathrm{C}$ \\
\hline \multicolumn{5}{|c|}{ Índice Priorização(IP) } & 50 & 75 & 5 & 415 & 403 & 128 & 136 & 314 & 0 \\
\hline \multicolumn{5}{|c|}{ Ordem Priorização } & - & - & - & $1^{\circ}$ & $2^{\circ}$ & $5^{\circ}$ & $4^{\circ}$ & $3^{\circ}$ & - \\
\hline \multicolumn{5}{|c|}{ Facilidade Ajuste } & 7 & 7,5 & 10 & 4,5 & 4,5 & 3 & 3 & 8 & 20 \\
\hline \multicolumn{5}{|c|}{ IP revisto } & 7 & 10 & 1 & 92 & 90 & 43 & 45 & 39 & 0 \\
\hline \multicolumn{5}{|c|}{ Ordem Priorização } & - & - & - & $1^{\mathrm{o}}$ & $2^{\circ}$ & $4^{\circ}$ & $3^{\circ}$ & $5^{\circ}$ & - \\
\hline \multicolumn{5}{|c|}{ Fatores Selecionados } & - & - & - & $X$ & $\mathrm{X}$ & $\mathrm{X}$ & $X$ & - & - \\
\hline \multicolumn{5}{|c|}{ Efeito Quadrático } & - & - & - & $\mathrm{S}$ & $\mathrm{S}$ & $\mathrm{N}$ & $\mathrm{N}$ & - & - \\
\hline \multicolumn{5}{|c|}{ Nível fatores fixos } & 60 & 1200 & com & - & - & - & - & - & - \\
\hline
\end{tabular}

(Legenda: $\mathrm{Mm}=$ maior é melhor; $\mathrm{mm}=$ menor é melhor). 


\subsection{Planejamento e execução dos experi- mentos}

Para que um experimento se realize de forma eficiente, devem-se empregar métodos científicos no seu planejamento (Montgomery, 1999). Dados sobre um problema podem não ser necessariamente oriundos de experimentos planejados e realizados especificamente para esse fim. A coleta de dados pode ser feita, por exemplo, durante a manufatura normal de um produto, desde que a coleta seja estruturada por meio do método de projeto de experimentos (Caten, 1995).

Para planejar e executar um experimento industrial é necessário que a equipe técnica identifique os parâmetros com maior probabilidade de influenciar a qualidade dos itens produzidos. Dentre os possíveis parâmetros de produto e processo, a equipe técnica deve definir aqueles a serem alterados durante o experimento; estes são os fatores controláveis do experimento. Fatores controláveis devem ser especificados quanto ao seu intervalo de estudo, número de níveis e quanto à possível ocorrência de interação entre fatores (Montgomery, 1999). Parâmetros não alterados no experimento devem ser mantidos fixos ou constantes, para reduzir o erro experimental. Fatores de ruído, responsáveis pelo erro experimental, também devem ser identificados com vistas à diminuição de seus efeitos sobre as características de qualidade. Finalmente, o número de rodadas no experimento deve ser definido considerando restrições financeiras e técnicas (Caten, 1995). Uma família especial de projeto experimental adequada para estudar, de forma eficiente e econômica, o efeito conjunto de vários fatores sobre uma ou mais características de qualidade são os experimentos fatoriais (Werkema e Aguiar, 1996b).

Uma vez definidas as características de qualidade a serem otimizadas no experimento, listam-se os parâmetros de processo a serem investigados. Desejam-se parâmetros que influenciem as características de qualidade. $\mathrm{O}$ cruzamento entre características de qualidade e parâmetros de processo utiliza o QFD.

O esquema operacional do QFD é o seguinte. Considere uma estrutura composta por $I$ linhas $(i=1, \ldots, I)$ e $J$ colunas $(j=1, \ldots, J)$ relacionáveis que formam uma matriz, além de um número adicional de linhas e colunas que não se cruzam na estrutura. Desejam-se valores numéricos ou pesos, designados por $I P_{j}$, que permitam ordenar os elementos listados nas colunas conforme sua importância relativa. Para tanto, duas informações são usadas: i) pesos de importância $I R_{i}$ atribuídos aos elementos listados nas $I$ linhas da matriz; e ii) medições numéricas do relacionamento entre os elementos nas $I$ linhas e $J$ colunas da matriz, $I Q_{i j}$, para todo $i$ e $j$. O índice $I P_{j}$ é, então, determinado por meio da relação (Mury e Fogliatto, 2002):

$$
I P_{j}=\sum_{i=1}^{n}\left(I R_{i} \times I Q_{i j}\right), j=1, \ldots, J .
$$

A intensidade dos relacionamentos $I Q_{i j}$ pode ser quantificada utilizando uma escala com valores entre 0 e 9 , em que 0 denota inexistência de relação entre os elementos $i$ e $j$, e 9 indica dependência máxima entre os elementos; demais valores na escala descrevem situações intermediárias. No contexto de um planejamento experimental, os elementos $i$ e $j$ correspondem às características de qualidade e parâmetros de processo, respectivamente. O estabelecimento das relações para cada par $(i, j)$ deve descrever o efeito sobre a $i$-ésima característica de qualidade de modificações efetuadas nos níveis do $j$-ésimo parâmetro de processo.

O índice $I P_{j}$ pode ser ajustado de forma a expressar a facilidade de ajuste do $j$-ésimo parâmetro do processo. Seja $D A_{j}$ o índice que denota a dificuldade de ajuste do parâmetro em questão (ajustes no processo e nas matérias-primas) durante a execução do experimento. Tal índice pode ser quantificado utilizando-se uma escala com valores entre 1 e 20, em que 1 representa um ajuste fácil, 10 representa um ajuste muito difícil e 20 representa um ajuste impossível. O índice de priorização $I P_{j}$ revisto é designado por $I P R_{j}$, sendo dado pela equação:

$$
I P R_{j}=\frac{I P_{j}}{D A_{j}}, j=1, \ldots, J .
$$

A Tabela 1 mostra a lista de características de qualidade, sua importância relativa, a lista de parâmetros de processo, bem como os resultados da avaliação da intensidade dos relacionamentos entre características de qualidade e parâmetros de processo para o estudo de caso. Informações adicionais acerca das características de qualidade e parâmetros de processo também são apresentadas na Tabela 1.

A análise dos valores de $I P R_{j}$ resultantes na matriz levou a quatro parâmetros de processo prioritários para investigação; são eles: tempo de resfriamento $\left(x_{1}\right)$; temperatura do fluido $\left(x_{2}\right)$; percentual de elastômero $\left(x_{3}\right)$; e percentual de talco $\left(x_{4}\right)$. Tais parâmetros constituem os fatores controláveis do experimento, sendo codificados de $x_{1}$ a $x_{4}$, conforme apresentado acima. Os parâmetros de processo a serem mantidos constantes no experimento são temperatura do molde, pressão de injeção e presença de gabarito.

Uma vez definidos o número de fatores controláveis e seus respectivos intervalos de investigação, procedeu-se à análise do projeto experimental mais adequado para a situação em questão. O projeto selecionado foi um fatorial $2^{\mathrm{k}}$ completo que permite capturar os efeitos principais e interações entre os fatores controláveis. Foi adicionado aos tratamentos experimentais um ponto central, com níveis intermediários dos fatores controláveis, para verificar a presença de efeitos não-lineares dos fatores controláveis sobre as variáveis de resposta. 
A correta execução do procedimento de coleta de dados deve seguir de maneira acurada o roteiro planejado. Monitorar o progresso do experimento é importante nesta etapa, pois erros de procedimento podem anular a sua validade. Dados auxiliares e modificações feitas sobre o planejamento inicial na etapa de execução devem ser registradas (Werkema e Aguiar, 1996a).

Para o caso em estudo, não foram realizadas réplicas das rodadas experimentais devido à inviabilidade econômica e à dificuldade de interromper a produção para a realização dos ensaios. O experimento foi dividido em dois blocos. A blocagem de experimentos consiste na divisão balanceada de suas rodadas experimentais com vistas a uniformizar o efeito de um fator, controlável ou de ruído, sobre o experimento. No caso em estudo, a blocagem teve por objetivo uniformizar o efeito da temperatura no ambiente de execução das rodadas experimentais.

Uma vez rodados os tratamentos experimentais, obtiveram-se peças a ser analisadas quanto às variáveis de resposta (características de qualidade listadas na Tabela 1). Ensaios para medição de cada característica de qualidade foram realizados utilizando equipamentos específicos. A análise das características de qualidade degradação foi realizada colocando-se os corpos de prova em um dispositivo desenvolvido para acelerar o processo de degradação. Uma vez expostas à degradação de intensidade pré-estabelecida, as peças foram submetidas a uma avaliação visual para determinar o seu estado de degradação. Essa avaliação visual foi realizada, inicialmente, comparando-se as peças com uma peça padrão e, posteriormente, transformando-se essa comparação em uma escala de intensidade numérica.

\subsection{Modelagem das variáveis de resposta}

A partir dos resultados de um experimento, podemse obter modelos de regressão, relacionando variáveis de resposta aos fatores controláveis. Variáveis de resposta podem incluir valores médios das características de qualidade observados em cada tratamento experimental ou a variância das características de qualidade em cada tratamento, no caso de experimentos com múltiplas realizações de um mesmo tratamento. A modelagem da média permite otimizar as características de qualidade quanto aos seus valores-alvo. A modelagem da variância visa maximizar a robustez do produto, reduzindo a sensibilidade do produto a variações nos fatores de ruído. Diferentes tipos de regressão podem ser utilizados nesta etapa. Para uma descrição detalhada da utilização da análise de regressão em um contexto de otimização multiresposta, ver Fogliatto e Albin (2000) e Ribeiro et al. (2000).

No estudo de caso em questão, utilizou-se regressão linear múltipla na modelagem das médias das características de qualidade. Somente fatores significativos $(p<0,10)$ foram incluídos nos modelos, com exceção do modelo para $Y_{4}$, como justificado na seqüência. Os coeficientes de determinação $\left(R^{2}\right)$ permitem avaliar a representatividade das equações de regressão obtidas. Informações acerca dos modelos de regressão vêm apresentadas na Tabela 2. No modelo, após cada termo, encontra-se entre parênteses o valor de $p$.

Os ensaios da variável de resposta impacto $\left(Y_{4}\right)$ foram realizados em equipamento próprio, pela empresa fornecedora da matéria-prima que compõe o produto. Por força da tecnologia disponível para realização dos ensaios, a variável impacto é mensurada por meio de três outras variáveis a ela relacionadas; são elas: Carga Máxima dada em kilo-Newtons ( $\mathrm{kN})$; Deflexão da Carga Máxima, dada em milímetros (mm); e Energia de Carga Máxima, dada em Joules (J). Por ser uma variável composta, é esperado que os valores de medição obtidos para a variável Impacto apresentem uma maior variabilidade. Na prática, essa variabilidade excessiva pode dificultar a obtenção

Tabela 2. Modelos de regressão obtidos para as variáveis de resposta.

\begin{tabular}{|c|c|c|}
\hline VR & $\mathbf{R}^{2}(\%)$ & Modelo \\
\hline$\left(Y_{1}\right)$ Dureza Rockwell & 73,25 & $\begin{array}{l}Y_{1}=65,85(0,0000)+1,78 X_{2}(0,0030)-1,11 X_{1} X_{4}(0,0591)-4,47 X_{3} X_{4}(0,000) \\
+2,65 X_{1} X_{2} X_{3}(0,000)+4,98 X_{1} X_{2} X_{4}(0,000)\end{array}$ \\
\hline$\left(Y_{2}\right)$ Degradação & 95,20 & $\begin{array}{l}Y_{2}=0,06(0,000)-0,005 X_{3}(0,0606)-0,013 X_{4}(0,014)+0,005 X_{1} X_{2}(0,0704)+0,005 X_{1} X_{3}(0,0606) \\
+0,01 X_{3} X_{4}(0,0020)+0,007 X_{1} X_{2} X_{3}(0,0203)+0,006 X_{1} X_{2} X_{4}(0,0417)-0,009 X_{1} X_{3} X_{4}(0,0080) \\
-0,006 X_{2} X_{3} X_{4}(0,0335)+0,005 X_{1} X_{2} X_{3} X_{4}(0,0521)\end{array}$ \\
\hline$\left(Y_{3}\right)$ Custo & 96,52 & $Y_{3}=28,69(0,0)+0,1075 X_{3}(0,0)+0,08 X_{4}(0,0)+0,26 X_{1}(0,0)$ \\
\hline$\left(Y_{4}\right)$ Impacto carga max. & 55,82 & $\begin{array}{l}Y_{4}=1,43(0,000)-0,13 X_{1}(0,1505)+0,15 X_{2}(0,0990)-0,14 X_{4}(0,1323)-0,14 X_{1} X_{4}(0,1323) \\
-0,15 X_{1} X_{2} X_{3}(0,1066)\end{array}$ \\
\hline$\left(Y_{5}\right)$ Impacto deflexão & 66,44 & $\begin{array}{l}Y_{5}=2,56(0,000)-0,34 X_{2}(0,0601)-0,35 X_{4}(0,0585)-0,34 X_{1} X_{2}(0,0608)+0,35 X_{3} X_{4}(0,0548) \\
-0,33 X_{2} X_{3} X_{4}(0,0721)\end{array}$ \\
\hline$\left(Y_{6}\right)$ Impacto energia & 98,20 & $\begin{array}{l}Y_{6}=1,99(0,000)-0,11 X_{2}(0,0371)-0,38 X_{4}(0,0001)-0,31 X_{1} X_{2}(0,0003)+0,18 X_{2} X_{3}(0,0054) \\
-0,12 X_{2} X_{4}(0,0294)+0,20 X_{3} X_{4}(0,0036)-0,20 X_{1} X_{2} X_{3}(0,0032)-0,41 X_{1} X_{2} X_{4}(0,0001)+ \\
0,14 X_{1} X_{3} X_{4}(0,0187)-0,16 X_{2} X_{3} X_{4}(0,0105)\end{array}$ \\
\hline
\end{tabular}


do modelo de regressão, associando impacto para a carga máxima com os fatores de controle do experimento. Foi exatamente essa a situação ocorrida neste estudo de caso, o que levou a um modelo para $Y_{4}$ com termos significativos a $85 \%$ ou mais, como mostra a Tabela 2.

A representação gráfica do efeito dos fatores controláveis significativos sobre as variáveis de resposta em um experimento costuma auxiliar na visualização do significado dos modelos de regressão obtidos para cada característica de qualidade (CQ). As Figuras de 1 a 5 apresentam o efeito dos fatores controláveis, significativos no modelo, sobre a variável de resposta Dureza Rockwell. A Figura 6 e a Figura 7 apresentam o efeito dos fatores controláveis, significativos no modelo, sobre a variável de resposta Avaliação da Degradação.

O experimento de degradação dos pisos plásticos foi realizado colocando-se os pisos em um dispositivo desenvolvido para acelerar o processo de degradação, simulando seu uso em campo. Uma vez expostas à degradação de intensidade pré-estabelecida, as peças foram submetidas a uma avaliação visual para determinar o seu nível de degradação. Essa avaliação visual foi feita com base na percepção dos avaliadores. A equipe de avaliadores foi apresentada às amostras resultantes dos ensaios, uma das quais identificada como elemento de controle. A equipe avaliou as amostras, referente à característica desgaste pelo uso, comparando-as com o elemento de controle. As amostras, quando comparadas com o elemento de controle, têm, em relação à referida característica, desgaste igual, maior ou menor. As avaliações utilizaram a escala numérica sugerida por Fogliatto et al. (2000).

\subsection{Otimização}

Uma vez identificados os modelos de regressão para as características de qualidade de interesse, deve-se selecionar uma função objetivo que permita a sua otimização simultânea. A otimização simultânea implica numa solução conciliatória que pondere as importâncias relativas de cada característica de qualidade sobre o produto final.

No estudo de caso, utilizou-se uma simplificação da função de perda quadrática multivariada em Ribeiro e Elsayed (1995), como função objetivo para otimização simultânea das características de qualidade do experimento. A simplificação da função perda utilizada é dada por:

$$
\hat{z}(\mathrm{x})=\sum_{i=1}^{I} w_{i}\left[\left(\hat{Y}_{i}(\mathrm{x})-\tau_{i}\right)^{2}\right]
$$

Em que:

$\hat{z}(\mathrm{x})$ - perda correspondente ao ajuste $\mathrm{x}$ do vetor de fatores controláveis;

$\hat{Y}_{i}(\mathrm{x})$ - valor esperado da $i$-ésima característica de qualidade para o ajuste $\mathrm{x}$ do vetor de fatores controláveis;

$w_{i}$ - fator de importância e correção de escala correspondente à $i$-ésima característica de qualidade; e

$\tau_{i}$ - valor-alvo para a $i$-ésima característica de qualidade.

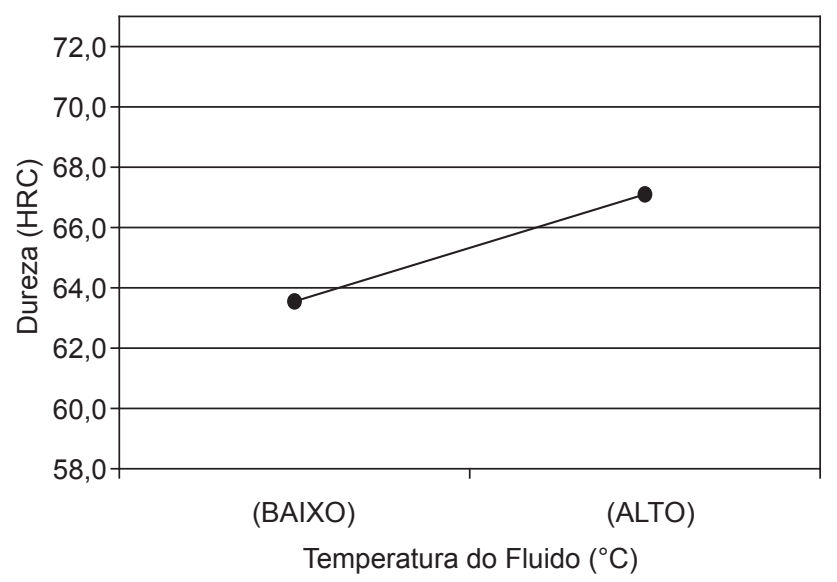

Figura 1. Representação gráfica do efeito do fator Temperatura do Fluido $\left(\mathrm{x}_{2}\right)$ sobre a CQ Dureza Rockwell.

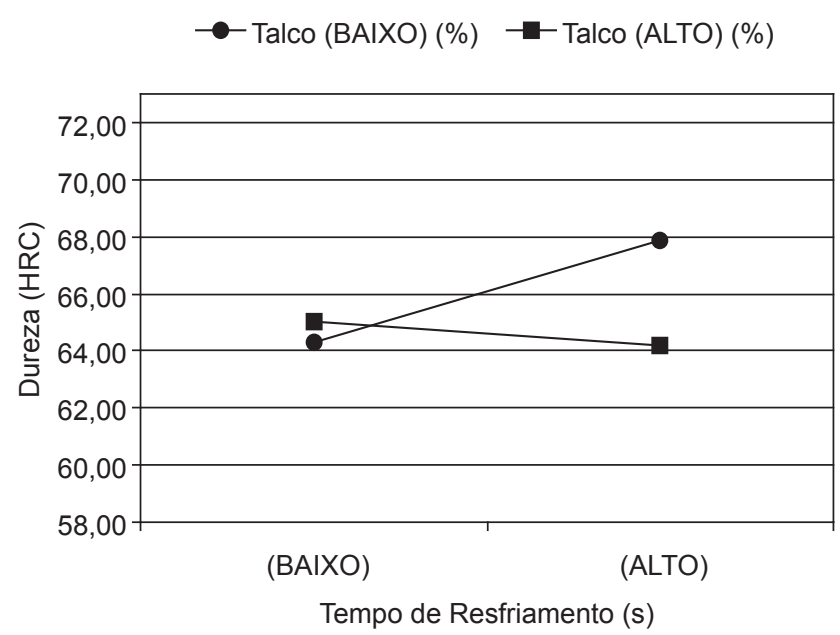

Figura 2. Representação gráfica do efeito da interação entre os fatores Tempo de Resfriamento (x1) e Talco (x4) sobre a CQ Dureza Rockwell.

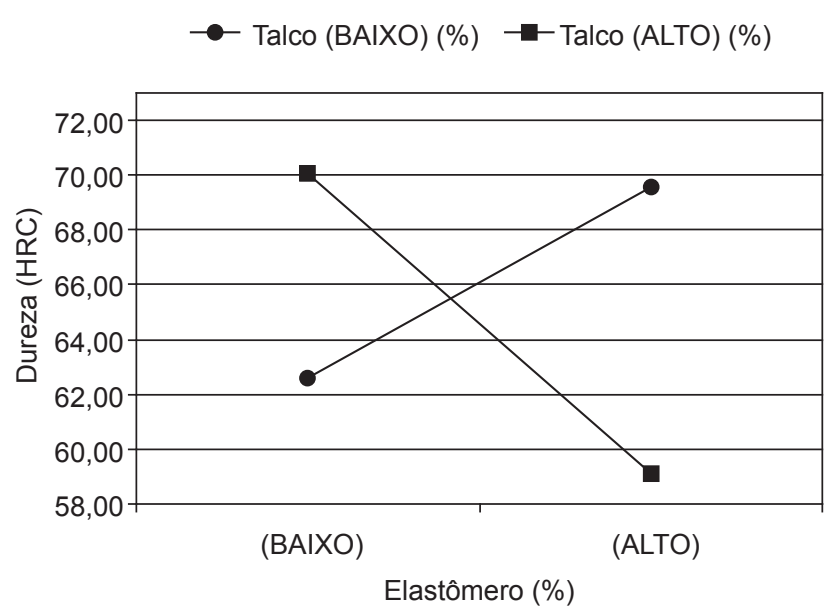

Figura 3. Representação gráfica do efeito da interação entre os fatores Elastômero (x3) e Talco (x4) sobre a CQ Dureza Rockwell. 

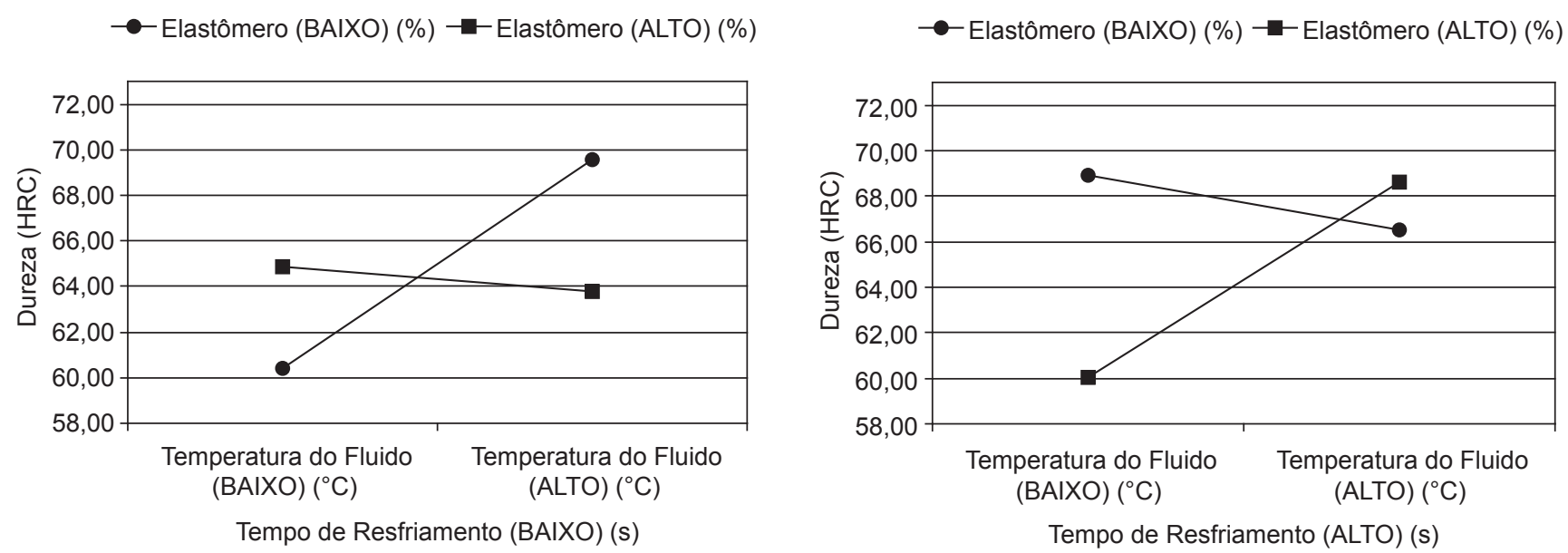

Figura 4. Representação gráfica do efeito da interação entre os fatores Tempo de Resfriamento (x1), Temperatura do Fluido (x2) e \% Elastômero (x3) sobre a CQ Dureza Rockwell.
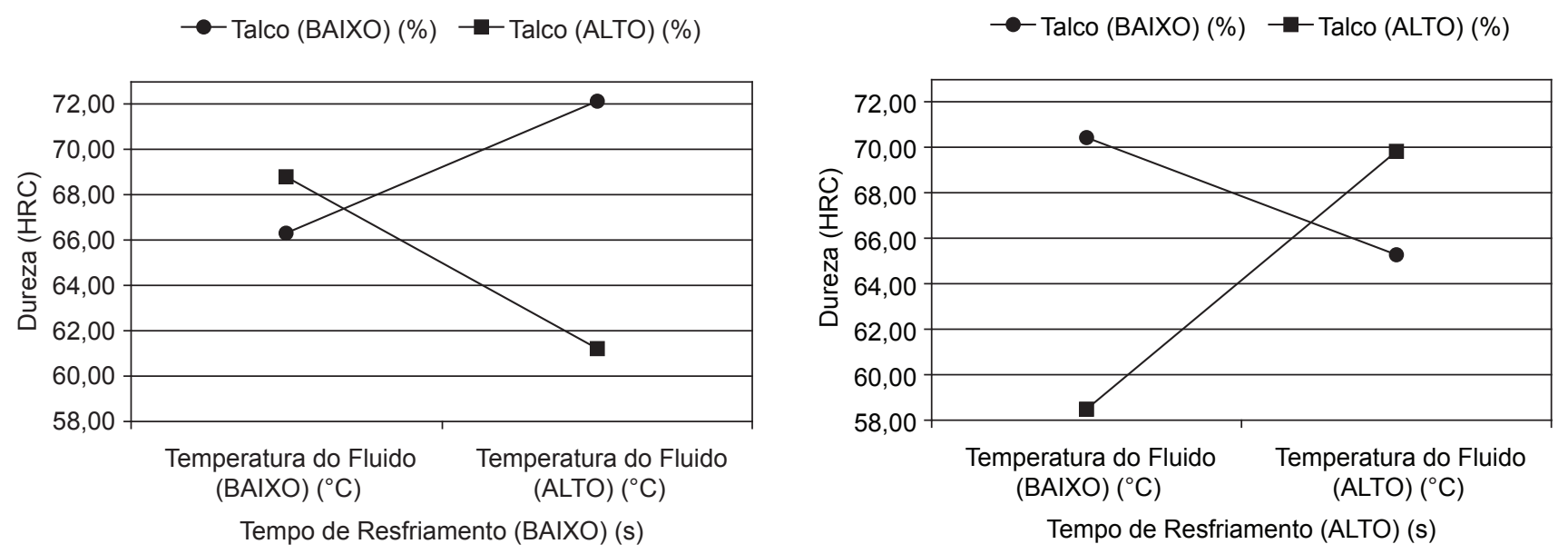

Figura 5. Representação gráfica do efeito da interação entre os fatores Tempo de Resfriamento (x1), Temperatura do Fluido (x2) e \% Talco (x4) sobre a CQ Dureza Rockwell.

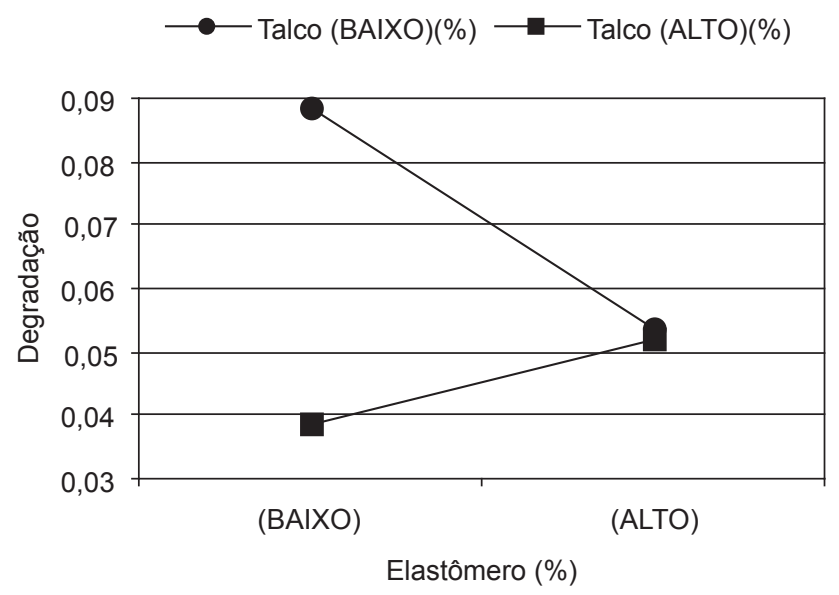

Figura 6. Representação gráfica do efeito da interação entre os fatores \% Elastômero (x3) e \% Talco (x4) sobre a CQ Avaliação da Degradação.

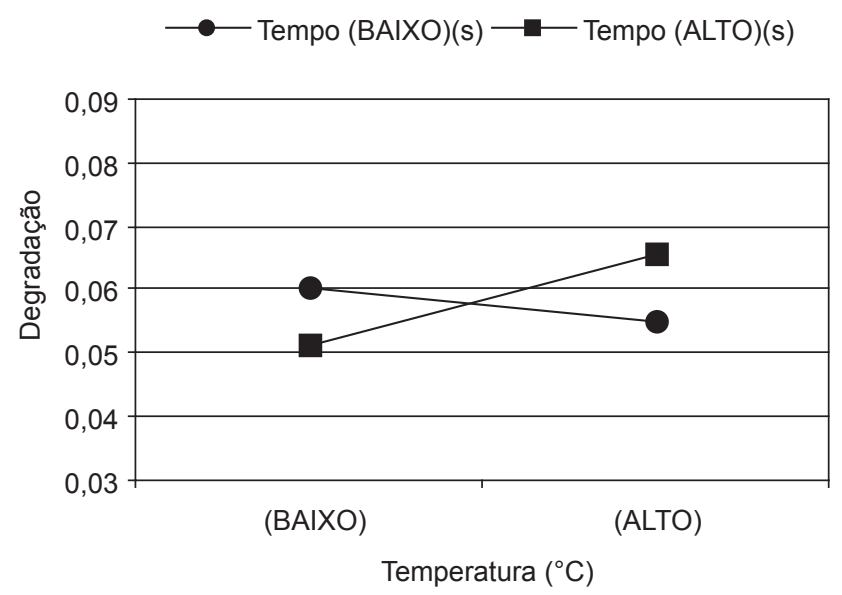

Figura 7. Representação gráfica do efeito da interação entre os fatores Tempo de Resfriamento (x1) e Temperatura do Fluido (x2) sobre a CQ Avaliação da Degradação. 
O fator de importância e correção de escala $w_{i}$ na Equação 3 considera a importância relativa $I R_{i}$ de cada característica de qualidade e normaliza os desvios do alvo, para que todas as características de qualidade possam ser diretamente comparáveis entre si. Os valores para $w_{i}$ são obtidos utilizando-se as expressões da Tabela 3, conforme o tipo de variável de resposta e seus respectivos valores alvo $\tau_{i}$, o limite superior (LS) e o limite inferior (LI), e conforme a importância relativa $I R_{i}$ de cada VR.

A otimização, utilizando a Equação 3 como funçãoobjetivo, busca determinar o ajuste dos fatores controláveis que minimiza a perda $Z$; tal ajuste é aquele que melhor satisfaz o conjunto das características de qualidade simultaneamente.

O ajuste dos fatores controláveis, considerando cada característica de qualidade individualmente e, então, simultaneamente, é apresentado na Tabela 4.
$\mathrm{Na}$ Tabela 4, as colunas 2, 3, 4 e 5 referem-se aos quatro fatores de controle do experimento. As colunas 6, 7, 8, 9 e 10 referem-se às características de qualidade avaliadas no experimento. Considerando a meta para cada característica de qualidade (ver Tabela 1) e os valores observados em cada rodada experimental, é possível identificar a melhor amostra em cada caso. Tal resultado também pode ser encontrado analisando as superfícies de resposta geradas para cada característica de qualidade, usando as expressões da Tabela 2, conforme proposto por Khuri e Cornell (1996). A coluna 11 refere-se à perda global, considerando simultaneamente as múltiplas características de qualidade. A coluna 12 refere-se ao custo correspondente a cada tratamento experimental e a coluna 13 refere-se à otimização, considerando simultaneamente as múltiplas características de qualidade e a variável de custo.

Tabela 3. Expressões para determinação de $w$.

\begin{tabular}{cccc}
\hline Tipo de VR & Maior é melhor & Menor é melhor & Nominal é melhor \\
\hline Expressão para $w_{i}$ & $w_{i}=\frac{I R_{i}}{\left(\tau_{i}-\mathrm{LI}\right)^{2}}$ & $w_{i}=\frac{I R_{i}}{\left(\mathrm{LS}-\tau_{i}\right)^{2}}$ & $w_{i}=\frac{I R_{i}}{[(\mathrm{LS}-\mathrm{LI}) / 2]^{2}}$ \\
\hline
\end{tabular}

Fonte: Caten e Pizzolato (2001).

Tabela 4. Resumo da otimização individual e simultânea das características de qualidade.

\begin{tabular}{|c|c|c|c|c|c|c|c|c|c|c|c|c|}
\hline 1 & 2 & 3 & 4 & 5 & 6 & 7 & 8 & 9 & 10 & 11 & 12 & 13 \\
\hline 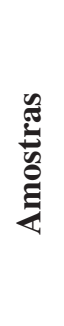 & 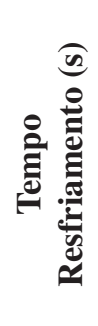 & 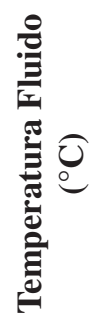 & 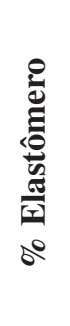 & $\begin{array}{l}\frac{8}{\tilde{J}} \\
\frac{\sqrt[J]{u}}{2} \\
0^{\circ}\end{array}$ & 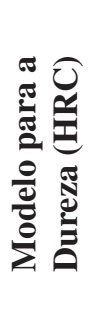 & 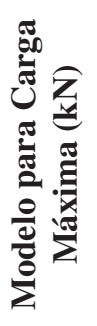 & 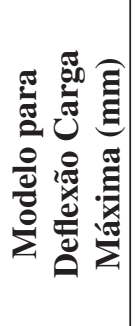 & 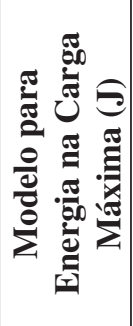 & 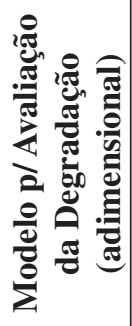 & 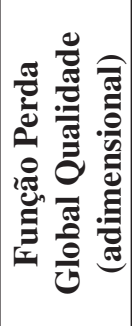 & 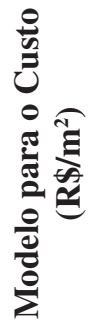 & 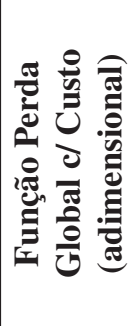 \\
\hline 1 & 70 & 209 & 0 & 0 & 50,86 & 1,560 & 3,591 & 3,071 & 0,107 & 0,253 & 28,24 & 0,253 \\
\hline 2 & 90 & 210 & 5 & 3 & 50,86 & 1,025 & 3,584 & 3,083 & 0,032 & 0,561 & 29,14 & 0,778 \\
\hline 3 & 70 & 251 & 5 & 3 & 56,64 & 1,867 & 2,239 & 2,391 & 0,027 & 0,419 & 28,62 & 0,458 \\
\hline 4 & 90 & 253 & 0 & 0 & 56,64 & 1,887 & 2,246 & 2,683 & 0,066 & 0,222 & 28,76 & 0,294 \\
\hline 5 & 70 & 212 & 5 & 0 & 65,10 & 1,260 & 2,229 & 1,868 & 0,035 & 0,370 & 28,46 & 0,383 \\
\hline 6 & 90 & 210 & 0 & 3 & 65,10 & 0,725 & 2,221 & 2,061 & 0,039 & 0,463 & 28,92 & 0,587 \\
\hline 7 & 70 & 255 & 0 & 3 & 70,88 & 1,567 & 2,186 & 1,813 & 0,044 & 0,253 & 28,40 & 0,260 \\
\hline 8 & 90 & 251 & 5 & 0 & 70,88 & 1,587 & 2,194 & 2,286 & 0,076 & 0,119 & 28,98 & 0,265 \\
\hline 9 & 80 & 231 & 2,5 & 1,5 & 65,85 & 1,435 & 2,561 & 1,992 & 0,059 & 0,227 & 28,69 & 0,281 \\
\hline 10 & 90 & 211 & 0 & 0 & 68,34 & 1,280 & 4,279 & 2,728 & 0,083 & 0,217 & 28,76 & 0,290 \\
\hline 11 & 70 & 210 & 5 & 3 & 68,34 & 1,260 & 2,896 & 0,956 & 0,086 & 0,208 & 28,62 & 0,247 \\
\hline 12 & 70 & 250 & 0 & 0 & 69,68 & 1,567 & 2,934 & 1,796 & 0,099 & 0,117 & 28,24 & 0,117 \\
\hline 13 & 90 & 250 & 5 & 3 & 69,68 & 1,032 & 1,551 & 0,808 & 0,066 & 0,280 & 29,14 & 0,497 \\
\hline 14 & 70 & 210 & 0 & 3 & 71,98 & 1,560 & 1,534 & 1,288 & 0,028 & 0,355 & 28,40 & 0,362 \\
\hline 15 & 90 & 210 & 5 & 0 & 71,98 & 1,580 & 2,916 & 1,791 & 0,062 & 0,185 & 28,98 & 0,332 \\
\hline 16 & 70 & 250 & 5 & 0 & 73,32 & 1,867 & 2,881 & 2,753 & 0,046 & 0,216 & 28,46 & 0,229 \\
\hline 17 & 90 & 250 & 0 & 3 & 73,32 & 1,332 & 1,499 & 0,496 & 0,048 & 0,304 & 28,92 & 0,428 \\
\hline
\end{tabular}


Os valores resultantes da otimização global foram obtidos com base na Importância Relativa, no tipo de características de qualidade, no valor-alvo e nos limites de especificação, definidos pela equipe da empresa e apresentados na Tabela 1. Na otimização global da qualidade, o melhor ensaio é o 12. Na otimização global, considerando também a variável de custo, o melhor ensaio também é o de número 12. Os ajustes dos parâmetros de processo para o ensaio 12 são Tempo de Resfriamento $=70 \mathrm{~s}$, Temperatura $=250{ }^{\circ} \mathrm{C}, \%$ de elastômero $=$ zero e $\%$ de talco $=$ zero. As características de qualidade resultantes desse processo otimizado são: Degradação $=0,099(0,028$ a 0,107); Custo $=\mathrm{R} \$ 28,24 / \mathrm{m}^{2} ;$ Dureza $=69,68 \mathrm{HRC}$; Impacto p/ Carga Máxima $=1,56 \mathrm{kN}$; Impacto p/ Deflexão Carga Máxima $=2,93 \mathrm{~mm}$; e Impacto p/ Energia Carga Máxima $=1,79 \mathrm{~J}$.

\subsection{Modelagem da vida útil e definição do prazo de garantia}

A definição do prazo de garantia é realizada com base na modelagem dos dados da vida útil do produto. É importante lembrar que a política de prazos de garantia de uma empresa é uma relação entre as suas expectativas de confiabilidade e expectativas financeiras. O prazo de garantia pode ser um importante promotor do produto, caso a política de prazos de garantia seja adequadamente definida em função do conhecimento da vida útil do produto.

Para definir a vida útil de um produto otimizado, recomenda-se a realização de testes acelerados de degradação. O planejamento e a execução de testes acelerados exigem técnicas específicas. Técnicas de planejamento e execução de testes de vida acelerados são detalhadas em Meeker e Hahn (1985), Nelson (1990), Meeker e Escobar (1993), Escobar e Meeker (1995), Elsayed (1996), Freitas e Colosimo (1997), e Park e Yum (1999). Planejamentos para testes de degradação acelerados podem ser encontrados em Boulanger e Escobar (1994), Park e Yum (1997), Yu e Tseng (1998; 1999), Park e Yum (1999), e Tseng e Yu (1997).

Para a definição do prazo de garantia de produtos, quando variáveis de degradação estiverem envolvidas, propõe-se seu desmembramento em fases da seguinte forma:

a) Definir a variável de resposta que avalia a vida útil do produto; caso o produto não apresente falhas, pode-se avaliar a queda do seu desempenho por meio de uma variável de degradação;

b) Definir a sistemática de medição da variável de resposta degradação, ou seja, como será a avaliação do produto exposto aos diferentes níveis de estresse; Definir o fator de estresse (X), responsável por acelerar a degradação do produto;

c) Definir os níveis do fator de estresse. A definição dos níveis deve ser feita baseada nas condições de uso do produto, evitando níveis muito distantes das condições normais de uso, pois isso pode produzir modos de falha indesejáveis e não representativos da operação do produto nas condições de projeto;

d) Modelar os dados da vida útil do produto, obtidos do teste de degradação acelerado, em função do fator de estresse $(X)$, por meio de análise de regressão;

e) Construir um intervalo de confiança para os valores previstos da variável de resposta de degradação $Y$;

f) Estabelecer um valor limite aceitável para a variável de resposta de degradação $(Y)$, acima do qual o produto deve ser substituído $\left(Y=Y_{0}\right)$; e

g) Identificar o valor do fator de estresse $(X)$ cujo limite superior do intervalo de confiança para o valor individual de $Y$ é o valor limite $Y_{0}$.

No caso em estudo, os ensaios de degradação foram executados em um dispositivo especialmente construído para simular o uso do produto no campo de forma acelerada. Após acompanhamento do uso do produto no campo e definida a relação entre a aceleração obtida no dispositivo e sua equivalência com o tempo real, foram definidos os níveis de estresse para a realização do teste acelerado.

Para determinar a equivalência entre o tempo real e o tempo acelerado no dispositivo, foi comparada uma peça em uso no campo com peças novas, colocadas no dispositivo e degradadas até obter uma equivalência com as peças degradadas em campo. O tempo necessário para degradar o produto no dispositivo passou a equivaler, então, ao tempo em dias de uso da peça em condições normais.

Os níveis de estresse em tempo de dispositivo estipulados para teste foram de 20 minutos, 63 minutos e 317 minutos; em tempo real, esses valores equivalem a 115 dias, 365 dias e 1825 dias, respectivamente. A escolha dos níveis para o teste acelerado deve-se ao conhecimento do produto e às informações de dados de garantia de produtos concorrentes. Obtiveram-se três amostras em cada nível de estresse, totalizando nove amostras.

Para a avaliação das peças submetidas ao teste de degradação acelerado, utilizaram-se técnicas de avaliação sensorial apresentadas em Fogliatto (1997) e Meilgaard et al. (1991). A avaliação das peças expostas a diferentes níveis de estresse foi feita comparando-as com um elemento de controle (ou peça limite). Para obter a peça limite, peças novas foram degradadas no dispositivo, até obter uma peça cuja degradação estivesse em seu limite de vida útil.

As peças obtidas em cada repetição do ensaio de degradação acelerado foram comparadas com a peça limite. As peças foram avaliadas utilizando-se uma escala de 1 a 10, em que 1 corresponde à condição menos degradada. 
A peça limite foi previamente colocada na escala e sua nota definida como 9, baseada em determinações da política de prazos de garantia da empresa. A nota 9 atribuída à peça limite permite verificar a ocorrência de peças mais degradadas do que ela. As nove peças foram comparadas com a mesma peça limite; dessa forma existe a possibilidade de se ter peças com nota menor (menos degradada), igual (mesma degradação) e maior (mais degradada) que a peça limite.

Para avaliadores dos resultados do teste acelerado de degradação, elegeram-se pessoas da empresa conhecedoras do produto, oriundas das áreas de desenvolvimento, processo, produção, vendas e assistência técnica. Foram observados procedimentos de treinamento de painelistas descritos em Meilgaard et al. (1991). Os avaliadores preencheram uma planilha, como a apresentada na Tabela 5. Os avaliadores realizaram suas avaliações individualmente, para evitar a indução nos resultados; evitou-se, também, qualquer marca nas peças que as diferenciasse das demais e que pudesse induzir as notas dadas pelos avaliadores. $\mathrm{O}$ registro das notas dadas pelos avaliadores são apresentadas na Tabela 6 .

As notas da degradação dadas pelos avaliadores foram submetidas a uma ANOVA, com resultados apresentados na Tabela 7. O objetivo da realização desta análise foi de identificar a existência de diferenças significativas entre os níveis de estresse e as notas dadas pelos avaliadores. Como se pode verificar na Tabela 7, os níveis de estresse e os avaliadores apresentam efeito significativo $(p<0,05)$ sobre a avaliação da degradação. Com base nessa informação, definiu-se que as notas dos avaliadores para posterior análise de regressão e obtenção do modelo seriam corrigidas, descontando-se o efeito do avaliador. A correção consiste em calcular a média das notas de cada avaliador, subtrair cada nota dada pelo avaliador da sua média e somar a média geral dos avaliadores (ver Tabela 8).

As notas corrigidas de cada avaliador (Tabela 9) foram utilizadas para realizar a análise de regressão linear simples, apresentada na Figura 8, da qual foi obtido o modelo de regressão para a vida útil do produto.
Os dados da Tabela 9 foram plotados no gráfico de dispersão da Figura 8, que sugere que o modelo que melhor se ajusta aos dados é um modelo logarítmico, em que $Y$ (nota de degradação) é função do logaritmo natural (ln) de $X$ (dias de uso). Chatterjee e Price (1991) afirmam que por meio da comparação dos gráficos de dispersão obtidos das variáveis em estudo pode-se definir qual forma de modelo linear representa melhor os dados. No gráfico da Figura 8, a variável independente $(X)$ representa o número de dias de uso do produto no campo, e a variável dependente $(Y)$ representa a nota corrigida da degradação do produto.

O modelo de regressão obtido para a vida útil foi:

$$
Y_{\text {nota }}=-6,26+1,90 \times \ln (D)
$$

O coeficiente de determinação do modelo na Equação 4 é $R^{2}=0,7697$. Para que um modelo obtido por meio de regressão linear seja considerado adequado, deve-se garantir que seus erros ou resíduos sigam uma distribuição normal, sendo distribuídos independentemente (aleatórios), com média 0 e variância constante (homogênea). A verificação da validade do modelo da vida útil é de-

Tabela 6. Notas da degradação.

\begin{tabular}{|c|c|c|c|c|c|c|}
\hline \multirow{2}{*}{$\begin{array}{c}\text { Níveis de } \\
\text { estresse }\end{array}$} & \multirow[t]{2}{*}{ Repetições } & \multicolumn{5}{|c|}{ Nota dada pelos avaliadores } \\
\hline & & Av1 & Av2 & Av3 & Av4 & Av5 \\
\hline N1 & R1 & 1,5 & 1,5 & 2 & 2 & 3,5 \\
\hline \multirow[t]{2}{*}{ (115 dias) } & $\mathrm{R} 2$ & 1,5 & 2,5 & 3 & 1,5 & 4,5 \\
\hline & R3 & 2 & 2 & 5 & 2,5 & 4,5 \\
\hline $\mathrm{N} 2$ & R1 & 4 & 6,5 & 3,5 & 3 & 6 \\
\hline \multirow{2}{*}{ (365 dias) } & R2 & 3,5 & 5,5 & 5,5 & 5 & 5 \\
\hline & R3 & 4,5 & 6 & 6 & 3 & 6,5 \\
\hline $\mathrm{N} 3$ & R1 & 8,5 & 8 & 7 & 7,5 & 6 \\
\hline \multirow[t]{2}{*}{ (1825 dias) } & R2 & 8 & 9 & 8,5 & 8 & 6,5 \\
\hline & R3 & 9 & 9,5 & 9,5 & 8,5 & 5,5 \\
\hline \multicolumn{2}{|c|}{ Média $\mathrm{p} /$ avaliador } & 4,722 & 5,611 & 5,556 & 4,556 & 5,333 \\
\hline \multicolumn{2}{|c|}{ Média geral } & 5,156 & & & & \\
\hline
\end{tabular}

Tabela 5. Planilha de avaliação da nota da degradação.

\begin{tabular}{|c|c|c|c|c|c|c|c|c|c|c|c|c|c|c|c|c|c|c|c|c|}
\hline & & 1 & 1,5 & 2 & 2,5 & 3 & 3,5 & 4 & 4,5 & 5 & 5,5 & 6 & 6,5 & 7 & 7,5 & 8 & 8,5 & 9 & 9,5 & 10 \\
\hline \multirow[t]{3}{*}{ N1 } & $\mathrm{R} 1$ & & & & & & & & & & & & & & & & & $\mathrm{~L}$ & & \\
\hline & $\mathrm{R} 2$ & & & & & & & & & & & & & & & & & $\mathrm{~L}$ & & \\
\hline & R3 & & & & & & & & & & & & & & & & & $\mathrm{L}$ & & \\
\hline \multirow[t]{3}{*}{$\mathrm{N} 2$} & $\mathrm{R} 1$ & & & & & & & & & & & & & & & & & $\mathrm{~L}$ & & \\
\hline & $\mathrm{R} 2$ & & & & & & & & & & & & & & & & & $\mathrm{~L}$ & & \\
\hline & R3 & & & & & & & & & & & & & & & & & $\mathrm{L}$ & & \\
\hline \multirow[t]{3}{*}{ N3 } & R1 & & & & & & & & & & & & & & & & & $\mathrm{L}$ & & \\
\hline & $\mathrm{R} 2$ & & & & & & & & & & & & & & & & & $\mathrm{~L}$ & & \\
\hline & R3 & & & & & & & & & & & & & & & & & $\mathrm{L}$ & & \\
\hline
\end{tabular}


Tabela 7. ANOVA dos níveis de estresse e dos avaliadores.

\begin{tabular}{lcrrrrr}
\hline Fonte da variação & SQ & Gl & MQ & F & valor-P & F crítico \\
\hline Níveis & 212,14 & 2 & 106,072 & 153,9758 & 0,0000 & 3,3158 \\
Avaliadores & 8,5222 & 4 & 2,13056 & 3,092742 & 0,0303 & 2,6896 \\
Interações & 33,578 & 8 & 4,19722 & 6,092742 & 0,0001 & 2,2662 \\
Dentro & 20,667 & 30 & 0,68889 & & & \\
Total & 274,91 & 44 & & & \\
\hline
\end{tabular}

Tabela 8. Notas corrigidas descontando o efeito do avaliador.

\begin{tabular}{lcccccc}
\hline $\begin{array}{c}\text { Níveis de } \\
\text { estresse }\end{array}$ & Repetições & \multicolumn{5}{c}{ Notas Corrigidas } \\
& & Av1 & Av2 & Av3 & Av4 & Av5 \\
\hline N1 & R1 & 1,93 & 1,04 & 1,60 & 2,60 & 3,32 \\
(115 dias) & R2 & 1,93 & 2,04 & 2,60 & 2,10 & 4,32 \\
& R3 & 2,43 & 1,54 & 4,60 & 3,10 & 4,32 \\
\hline N2 & R1 & 4,43 & 6,04 & 3,10 & 8,10 & 5,82 \\
(365 dias) & R2 & 3,93 & 5,04 & 5,10 & 5,60 & 4,82 \\
& R3 & 4,93 & 5,54 & 5,60 & 3,60 & 6,32 \\
\hline N3 & R1 & 8,93 & 7,54 & 6,60 & 8,10 & 5,82 \\
(1825 dias) & R2 & 8,43 & 8,54 & 8,10 & 8,60 & 6,32 \\
& R3 & 9,43 & 9,04 & 9,10 & 9,10 & 5,32 \\
\hline
\end{tabular}

Tabela 9. Análise de regressão da variável de degradação.

\begin{tabular}{lrrrr}
\hline \multicolumn{1}{c}{ Parâmetros } & Coef. & $\begin{array}{c}\text { Erro } \\
\text { padrão }\end{array}$ & Estatística $\boldsymbol{t}$ & Valor - $\boldsymbol{p}$ \\
\hline Interseção & $-6,26$ & 0,97755 & $-6,4084$ & 0,0000 \\
ln dos Dias de uso & 1,90 & 0,15878 & 11,9876 & 0,0000 \\
\hline
\end{tabular}

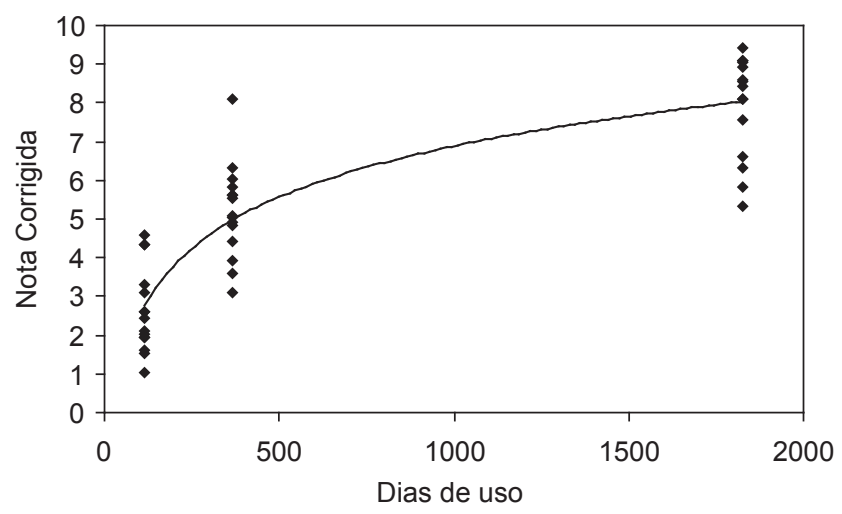

Figura 8. Gráfico de dispersão para a nota corrigida. monstrada pelos gráficos na Figuras 9 e 10. O gráfico da Figura 9, que apresenta os resíduos padronizados plotados contra os níveis da variável independente $(X)$, permite verificar a homogeneidade da variância. Para casos em que o uso da regressão inversa viola a suposição de homocedasticidade, ver Freitas et al. (2004) para um procedimento alternativo de análise. O gráfico da Figura 10 apresenta os resíduos padronizados ordenados, permitindo verificar a aleatoriedade dos resíduos.

Além das estimativas da intersecção da reta com o eixo $Y$ e da sua inclinação, também é possível obter intervalos de confiança (ICs) para as estimativas destes parâmetros. Segundo Montgomery e Runger (1999), o tamanho desse intervalo de confiança é uma medida da qualidade global do modelo de regressão.

Uma vez ajustado o modelo de regressão, calcula-se o intervalo de $95 \%$ de confiança para os valores previstos de $Y_{\text {nota }}$. A partir do modelo ajustado com o intervalo de confiança para $Y_{\text {nota }}$, pode-se definir o número de dias $(X)$ cujo limite superior do IC de $95 \%$ corresponda a $Y_{\text {nota }}=9$, que é a nota de degradação da peça limite acima da qual o produto chega ao fim de sua vida útil.

O intervalo de confiança para $Y_{\text {nota }}$ foi calculado utilizando o software StatGraphics (1995); este software utiliza para o cálculo do intervalo de confiança os conceitos apresentados por Montgomery (1997). A Figura 11 apresenta o modelo ajustado com o intervalo de confiança para os valores de $Y_{\text {nota }}$. Como se pode verificar na Figura 11, o logaritmo do número de dias, cujo limite superior do intervalo de confiança de $95 \%$ é $Y_{\text {nota }}=9$, corresponde a $\ln D=6,74$, ou seja, 845 dias. Verifica-se, então, que acima desse tempo o produto pode degradar mais do que o limite aceitável, tendo que ser substituído. Assim, baseada na modelagem da vida útil e no conhecimento do produto, a equipe técnica definiu como prazo de garantia para o produto o tempo de 2 anos.

\section{Conclusões}

Este artigo apresentou a aplicação de um método de otimização experimental e definição do prazo de garantia em um produto utilizado na criação de animais. Este método é constituído das etapas de: i) caracterização do 


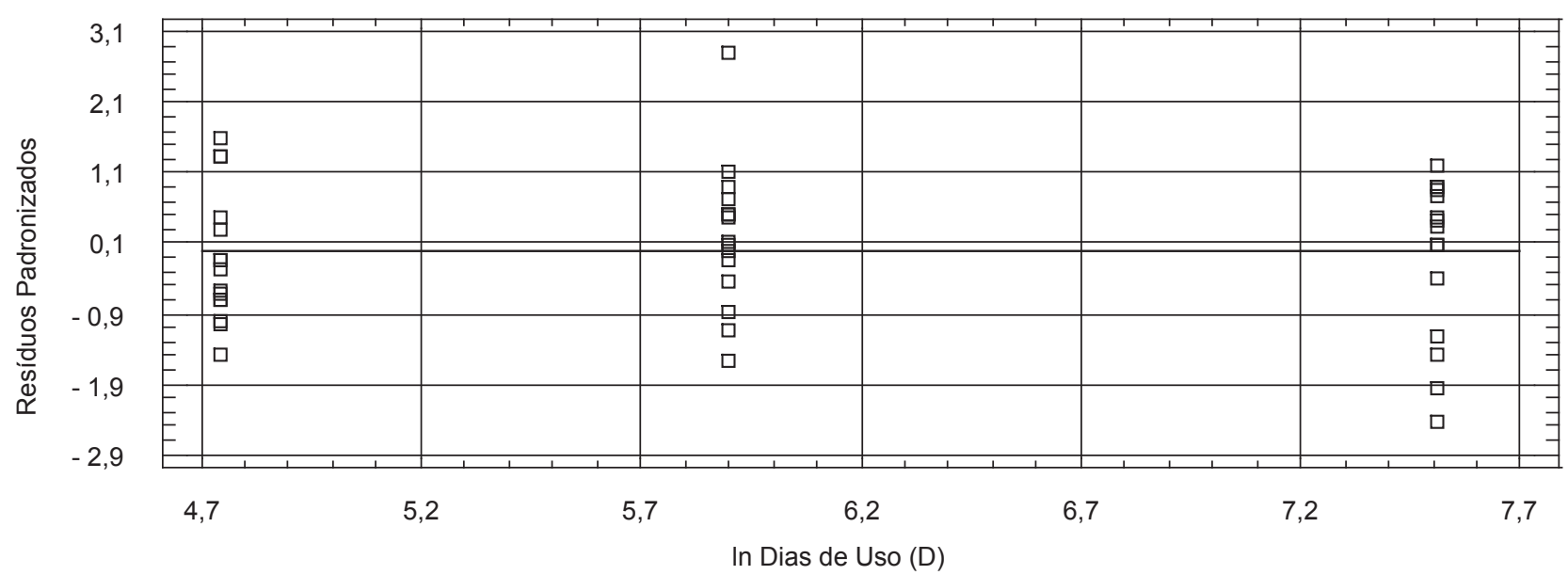

Figura 9. Gráfico dos resíduos padronizados x ln D.

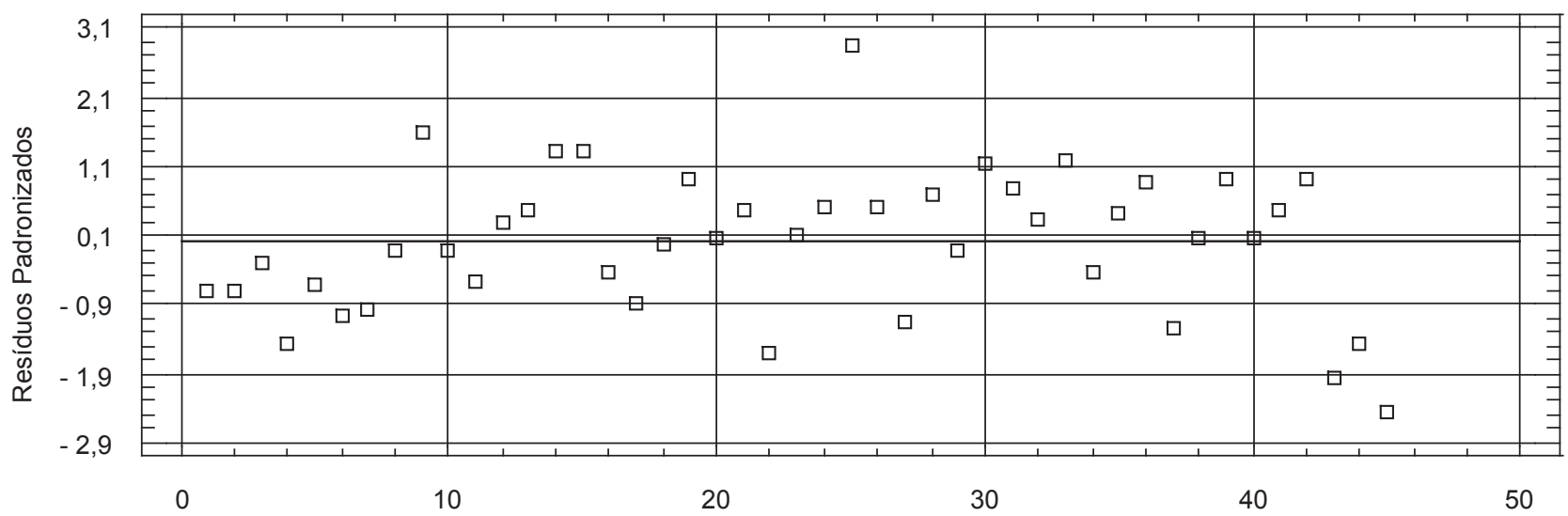

Figura 10. Gráficos dos resíduos $x$ ordem.

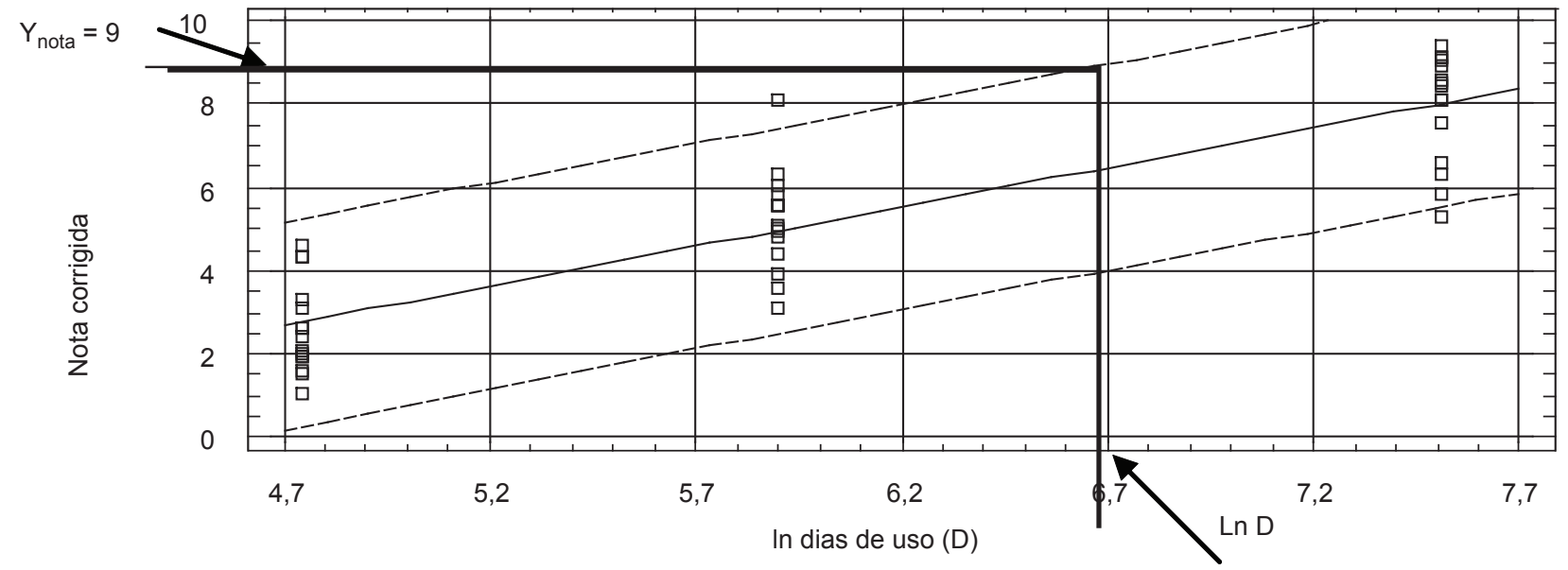

Figura 11. Gráfico do Modelo Ajustado com os Intervalos de Confiança para Y. 
problema; ii) planejamento e execução do experimento; iii) modelagem das variáveis de resposta; iv) otimização; e v) modelagem da vida útil.

O método de otimização foi aplicado na determinação dos melhores parâmetros de produção e composição de um piso plástico, utilizado em maternidades para suínos. Uma das variáveis de resposta do experimento foi a degradação dos pisos quando submetidos à desgaste acelerado por atrito; esta característica de qualidade avalia a vida útil do produto. A otimização global do experimento foi obtida com o seguinte ajuste dos fatores controláveis: Tempo de Resfriamento baixo (70 s), Temperatura alta $\left(250{ }^{\circ} \mathrm{C}\right), \%$ de elastômero zero e \% de talco zero. As características de qualidade resultantes desse processo otimizado são: Degradação 0,099 (0,028 a 0,107); Custo $\mathrm{R} \$ 28,24 / \mathrm{m}^{2}$; Dureza $69,68 \mathrm{HRC}$; Impacto $\mathrm{p} /$ Carga Máxima 1,56 kN; Impacto p/ Deflexão Carga Máxima 2,93 mm; e Impacto p/ Energia Carga Máxima 1,79 J.

A modelagem da vida útil de um piso plástico, utilizado em maternidades de suínos, foi realizada com base em dados provindos de testes de degradação acelerada. A medição da variável de resposta de degradação foi feita por meio de avaliação sensorial. O prazo de garantia definido para os pisos, com base na modelagem da vida útil de dados de teste de degradação acelerado, foi de 2 anos.

\section{Referências Bibliográficas}

AKAO, Y. Quality Function Deployment - Integrating Customer Requirements into Product Design. Cambridge: Productivity, 1990. 369 p.

Introdução ao Desdobramento da Qualidade. Belo Horizonte: Fundação Cristiano Ottoni, 1996. 187 p.

BOULANGER, M.; ESCOBAR, L . A. Experimental Design for a Class or Accelerated Degradation Tests. Technometrics, Alexandria/VA. v. 36, n. 3, p. 260-272, 1994.

CATEN, C. S. Método de otimização de produtos e processos medidos por múltiplas características de qualidade. 1995. 154 f.. Dissertação (Mestrado em Engenharia de Produção), Escola de Engenharia, Universidade Federal do Rio Grande do Sul, Porto Alegre, 1995.

CATEN, C. S.; PIZZOLATO, M. Método de Otimização Experimental da Qualidade e Durabilidade de um Produto. In: ENCONTRO NACIONAL DE ENGENHARIA DE PRODUÇÃO, 21., Salvador/BA, out/2001. Anais... CD-ROM.

CHATTERJEE, S.; PRICE, B. Regression Analysis by Example. 2. ed. New York: John Wiley and Sons, 1991.

ELSAYED, E. A. Reliability Engineering. Massachusetts: Addison Wesley, 1996.

ESCOBAR, L. A.; MEEKER, W. Q. Planning Accelerated Life Tests With Two or More Experimental Factors. Technometrics, Alexandria/VA. v. 37, n. 4, p. 411-427, 1995.

FACCIONI, L. P. Uma proposta para estudos de confiabilidade utilizando modelos de desempenho. 2000. 136 f.. Dissertação (Mestrado em Engenharia de Produção), Escola de Engenharia, Universidade Federal do Rio Grande do Sul, Porto Alegre, 2000.

FOGLIATTO, F. S.; ALBIN, S .L. Optimizing multiresponse experiments using the accuracy of prediction as an op- timization criterion. Quality Engineering, Philadelphia/ PA. v. 12, n. 4, p. 523-533, 2000.

FOGLIATTO, F. S. Hierarchical Multiresponse Optimization Method. 1997. Tese (Doutorado em Engenharia Industrial e de Sistema), Industrial \& Systems Engineering Department, Rutgers University, New Jersey, 1997.

FOGLIATTO, F. S.; ALBIN, S .L.; SILVA, A. M. S. A Method dos Sensory Data Collection and Analysis in Product Development. In: ENCONTRO NACIONAL DE ENGENHARIA DE PRODUÇÃO, 20., São Paulo/SP, out/2000. Anais... CD-ROM.

FREITAS, M. A.; BORGES, W.; HO, L. L. Sample plans comparisons for shelf life estimation using sensory evaluation scores. Int. J. Quality \& Reliability Management, West Yorkshire, England, v. 21, n. 4, p. 439-466, 2004.

FREITAS, M. A.; COLOSIMO, E. A. Confiabilidade: Análise de tempo de falha e testes de vida acelerados. Belo Horizonte: Fundação Christiano Ottoni, 1997. v. 12.

GOEL, P. S.; SINGH, N. A framework for integrating quality, reliability, and durability in product design with lifecycle cost considerations. Quality Engineering, Philadelphia/PA, v. 10, n 2, p. 267-281, 1998.

KHURI, A. I.; CORNELL, J. A. Response Surfaces. 2. ed. New York: Marcel Dekker, 1996.

MEEKER, W. Q.; ESCOBAR, L. A. A Review of Recent Research and Current Issues in Accelerated Testing. International Statistical Review, v. 61, n. 1, p. 147-168, 1993.

MEEKER, W. Q.; HAHN, G. J. How to Plan an Accelerated Life Test. ASQ Basic References in Quality Control: Satistical Techniques. Milwaukee: ASQ - Quality Press, 1985. v. 10. 
MEILGAARD, M.; CIVILLE, G. V.; CARR, B.T. Sensory Evaluation Techniques. 2. ed. Boca Ratón: CRC Press, 1991.

MONTGOMERY, D. C. Design and Analysis of Experiments. 5. ed. New York: John Wiley \& Sons, 1997.

MONTGOMERY, D. C.; RUNGER, G. C. Applied Statistics and Probability for Engineers. 2. ed. New York: John Wiley \& Sons, 1999.

MURY, L. G. M; FOGLIATTO, F. S. Adaptação de produtos para mercados diferenciados através da Engenharia Reversa. Produção, São Paulo, v.11, n. 2, p. 5-22, $\mathrm{abr} / 2002$.

NELSON, W. Graphical analysis of system repair data. Journal of Quality Techonology, Milwaukee, Wisconsin, v. 20, n. 1, p. 24-35, 1988.

. Accelerated testing: statistical models, test plans and data analysis. New York: John Wiley \& Sons, 1990. $601 \mathrm{p}$.

PARK, J. I.; YUM, B. J. Comparisions of Optimal Accelerated Test Plans for Estimating Quantiles of Lifetime Distribuition at the Use Condition. Engineering Optimization, Oxon, England, v. 31, n. 3, p. 301-328, 1999.

Optimal Design of Accelerated Degradation Tests for Estimating mean Life Time at the Use Condition. Engineering Optimization, Oxon, England, v. 28, n. 3, p. 199-230, 1997.

PIZZOLATO, M. Método de otimização experimental da qualidade e durabilidade de produtos: um estudo de caso em produto fabricado por injeção de plástico. 2002. 111 f.. Dissertação (Mestrado em Engenharia de Produção), Escola de Engenharia, Universidade Federal do Rio Grande do Sul, Porto Alegre, 2002.

RIBEIRO, J. L. D.; ELSAYED, E. A. A case study on process optimization using the gradient loss function. International Journal Prodution Research, Abingdon, United Kingdom, v. 33, n. 12, p. 3233-3248, 1995.
RIBEIRO, J. L. D.; ECHEVESTE, M. E.; DANILEVICZ, A. M. F. A utilização de QFD - Quality Deployment Function - na otimização de produtos, processos e serviços: disciplina de mestrado, realizada em outubro de 2000. Notas de Aula, elaboradas em 1999.

RIBEIRO, J. L. D.; FOGLIATTO, F. S.; CATEN, C. S. Minimizing Manufacturing and Quality Costs in Multiresponse Optimization. Quality Engineering, Philadelphia/ PA. v. 13, n. 2, p. 191-201, 2000.

SEBER, G. A. F. Multivariate observations. New York: John Wiley, 1984. 686 p.

STATGRAPHICS PLUS. User Manual. V. 2. Manugistics Inc., Rockville, Maryland, 1995.

TSENG, S. T.; YU, H. F. A Termination Rule for Degradation Experiments. IEEE Transactions on Reliability, v. 46, n. 1, p. 130-133, 1997.

WASSERMAN, G. S.; SUDJIANTO, A. A comparison of three strategies for forecasting warranty claims. IIE Transactions, Philadelphia/PA, v. 28, n. 4, p. 967-977, 1996.

WERKEMA, M. C. C.; AGUIAR, S. Otimização Estatística de Processos: Como determinar a condição de operação de um processo que leva ao alcance de uma meta de melhoria. Belo Horizonte: Fundação Christiano Ottoni, 1996a. 331 p. v. 9.

Planejamento e Análise de Experimentos: como identificar e avaliar as principais variáveis influentes em um processo. Belo Horizonte: Fundação Christiano Ottoni, 1996b. 294 p. v. 8.

YU, H.F.; TSENG, S.T. Designing a Degradation Experiment. Naval Research Logistics, Hoboken, NJ, v. 46, n. 6, p. 689-706, 1999.

. On-line Procedure for Terminating an Accelerated Degradation Test. Statistica Sinica, Taiwan, v. 8, n. 1, p. 207-220, 1998. 


\title{
DEFINITION OF THE WARRANTY PERIOD OF AN EXPERIMENTALLY OPTIMIZED PRODUCT
}

\begin{abstract}
This paper discusses the results of the application of a method to optimize the quality characteristics and service life of products that degrade rather than fail in order to determine the warranty period of such products. The optimization method consists of the following steps: $i$ ) characterization of the problem; ii) planning and execution of experiments; iii) modeling of response variables; iv) optimization; and v) modeling of the product's service life and definition of its warranty period. The method involves the joint use of QFD (Quality Function Deployment), Experimental Design, and modeling of accelerated degradation tests through regression analysis. A new procedure is presented to determine and optimize the warranty period of products subject to degradation, based on the sensorial analysis of sample products to assess their level of degradation. The method is illustrated by a case study of the plastics industry, where the goal is to come up with a suitable warranty policy for plastic floor tiles in pigpens.
\end{abstract}

Keywords: optimization, accelerated degradation tests, product lifetime modeling. 